\title{
Estado e PCC na pandemia: convergências e divergências na proposição de medidas de saúde e segurança pública nas prisões
}

\author{
State and PCC during the pandemic: convergences and \\ divergences in the proposal of measures for health and \\ public security in prisons
}

\section{Estado y PCC en pandemia: convergencias y divergencias en la propuesta de medidas de salud y seguridad pública en las cárceles}

iD Thais Lemos Duarte
Universidade Federal de Minas Gerais, Belo Horizonte, Minas Gerais, Brasil thais-duarte@hotmail.com

(iD) Natália Martino

Universidade Federal de Minas Gerais, Belo Horizonte, Minas Gerais, Brasil natymartino@gmail.com

(iD) Ana Beraldo

Universidade Federal de Minas Gerais, Belo Horizonte, Minas Gerais, Brasil anaberaldopsi@gmail.com

Resumo: O artigo analisa embates e aproximações entre distintos atores - órgãos de Direitos Humanos e Conselho Nacional de Justiça (CNJ), Governo Federal e Tribunais de Justiça, e o Primeiro Comando da Capital (PCC) - no que se refere à emergência da Covid-19 e seu espraiamento nas prisões. A partir da análise de matérias jornalísticas, normativas, e dados estatísticos oficiais, argumenta-se que os discursos do PCC e as diretrizes internacionais e nacionais convergem no que tange a uma pauta central: a necessidade de redução da superlotação prisional. Por outro 
lado, governo e agentes de justiça mostram-se contrários ao desencarceramento de custodiados, alegando que poderia gerar insegurança à população. Em consequência, as já ruins condições carcerárias se tornam ainda mais precárias e a vida das pessoas privadas de liberdade ainda mais frágil. O efeito desse cenário é que o PCC assume o papel de defensor dos direitos dos presos, em potencial intensificação de sua legitimidade nas cadeias e periferias.

Palavras-chave: PCC. Garantias fundamentais. Covid-19. Políticas penais. Direito à vida.

Abstract: The article analyzes clashes and approaches between different actors - Human Rights bodies and the National Council of Justice (CNJ), Federal Government and Courts of Justice, and the First Command of the Capital (PCC) - regarding the emergence of Covid-19 and its spread in prisons. From the analysis of journalistic articles, norms, and official statistical data, it is argued that the speeches of the PCC and the international and national guidelines converge with respect to a central agenda: the reduction of prison overcrowding. On the other hand, government and justice agents are opposed to the release of custodians, claiming that it could endanger the population. Consequently, the already bad prison conditions become even more precarious and the lives of people deprived of their liberty even more fragile. The effect of this scenario is that the PCC assumes the role of defender of the rights of prisoners, in a potential intensification of their legitimacy in the jails and peripheries.

Keywords: PCC. Fundamental guarantees. Covid-19. Penal policies. Right to life.

Resumen: Este artículo analiza los enfrentamientos y convergencias que se dieron entre diferentes actores -Órganos de Derechos Humanos y Consejo Nacional de Justicia (CNJ), Gobierno Federal, Tribunales de Justicia y Primer Comando de la Capital (PCC)- en torno al surgimiento del Covid-19 y su propagación en las cárceles. Con base en el análisis de artículos periodísticos, normativa y datos oficiales, se argumenta que el discurso del PCC y los lineamientos internacionales y nacionales han 
tendido a convergir alrededor de una agenda central: la reducción del hacinamiento carcelario. Paralelamente, en la medida en que los agentes del gobierno y de la justicia se han opuesto a la liberación de los presos, alegando que ello podría generar un aumento de la inseguridad en la población, las ya deficitarias condiciones carcelarias se han vuelto aún más precarias y la vida de los internos más frágil. En este escenario, el PCC, que asume el rol de defensor de los derechos de los presos, puede potencialmente ampliar su legitimidad en las cárceles y periferias.

Palabras clave: PCC. Garantías fundamentales. Covid-19. Políticas penales. Derecho a la vida.

Data de recebimento: 15/10/2020

Data de aprovação: 25/02/2021 
Estado e PCC na pandemia: convergências e divergências na proposição de medidas de saúde... Thais Lemos Duarte $\bullet$ Natália Martino • Ana Beraldo

\section{Apresentação}

Em abril de 2020, durante uma coletiva de imprensa no Palácio do Planalto, o então Ministro da Saúde, Luiz Henrique Mandetta, indicou preparar uma estratégia de combate ao novo coronavírus específica para espaços de periferia: a partir do reconhecimento de que muitos desses territórios estão sob domínio de organizações criminais, afirmou que o Ministério da Saúde estaria disposto a travar conversas sobre o tema com chefes de redes de tráfico de drogas e das milícias. Caso contrário, não seria possível estabelecer medidas eficazes de prevenção à pandemia em áreas identificadas como "excluídas".

A saúde dialoga, sim, com o tráfico, com a milícia, porque também são seres humanos e precisam colaborar, ajudar, participar. Então, neste momento, quando a gente faz esse tipo de colocação, a gente deixa claro que todo mundo vai colaborar (no combate à Covid-19). (AGÊNCIA ESTADO, 8 abr. 2020).

4

A declaração se mostrou polêmica e gerou diversas reações negativas. Elio Gaspari, por exemplo, em sua coluna na Folha de São Paulo, afirmou que o então ministro Mandetta sofria de uma "síndrome do holofote", perdendo a oportunidade de ficar calado (GASPARI, 2020). O jornalista declarou que, embora o poder público dialogue com a "bandidagem" informalmente há décadas - o que teria se mostrado vital ao bom funcionamento de determinadas políticas públicas em muitos espaços periféricos -, a fala de Mandetta acabaria por legitimar grupos criminais. De igual maneira, o ex-ministro da Segurança Pública Raul Jungman disse entender as preocupações humanitárias do Ministério da Saúde, mas declarou que o posicionamento de Mandetta era "inaceitável" porque significaria "reconhecer o controle do crime organizado sobre a vida das pessoas" (DECLARAÇÃO..., 10 abr. 2020). Tomamos esse embate como ponto de partida para pensarmos alguns de- 
Estado e PCC na pandemia: convergências e divergências na proposição de medidas de saúde... Thais Lemos Duarte $\bullet$ Natália Martino • Ana Beraldo

safios suscitados pela emergência da pandemia da Covid-19 na área da segurança pública, especialmente no que se refere a seu espraiamento nas cadeias e prisões do país.

Sabemos que o encarceramento em massa, aliado à seletividade do sistema criminal, há muito converteu os espaços prisionais em componentes da paisagem urbana, identificados também como territórios periféricos (GODOI, 2015), ou mesmo "excluídos", conforme as palavras de Mandetta. Sendo o contexto prisional solo fértil para o surgimento e a articulação de grupos criminosos (LESSING, 2017), que se espraiam também pelos espaços de pobreza urbana, estes coletivos ganham centralidade no processo de formulação e de implementação de políticas públicas dentro e fora das grades, gerando um envolvimento entre atores estatais e dinâmicas ilegais na condução cotidiana de espaços marginais. Com a pandemia do novo coronavírus, não está sendo diferente.

Nesse sentido, buscamos entender como a interseção, proposta pelo ex-ministro, entre políticas de saúde e organizações criminais está presente na discussão e na construção de ações para combater o avanço do novo coronavírus no sistema penitenciário nacional. Para tanto, tomamos diferentes grupos de atores, como o Primeiro Comando da Capital (PCC), o Conselho Nacional de Justiça (CNJ) e tribunais de justiça estaduais como focos de nossas análises. Mais especificamente, buscamos compreender: a) como o PCC tem se posicionado e se articulado no interior do sistema prisional diante da pandemia do novo coronavírus; b) quais as recomendações elaboradas e difundidas pelo CNJ para lidar com a crise de saúde no ambiente carcerário e como os judiciários estaduais se apropriaram (ou não) de tais recomendações; e c) se existem (e quais são) as convergências e divergências entre esses posicionamentos. Em síntese, o objetivo deste artigo é analisar as reivindicações do PCC em face da atual crise de saúde, traçando um paralelo entre tais demandas e as medidas recomendadas e/ ou efetivamente postas em prática por distintos atores oficiais em relação à conjuntura da pandemia nas prisões. 
Estado e PCC na pandemia: convergências e divergências na proposição de medidas de saúde... Thais Lemos Duarte $\bullet$ Natália Martino • Ana Beraldo

A partir da análise de dados quantitativos, de narrativas da imprensa e de normativas publicadas recentemente, demonstraremos que, em alguma medida, as exigências elaboradas pelo PCC vão ao encontro de diretrizes emanadas pelo CNJ, as quais, por sua vez, são coerentes com as recomendações efetuadas por organizações internacionais de direitos humanos. Argumentamos, também, que a recusa de certos órgãos governamentais e de operadores do direito em atender essas normativas institucionais acaba por gerar - ou intensificar - uma série de violações de direitos de um segmento já vulnerável, como é a população carcerária. Nesse cenário, as demandas do PCC ganham mais espaço, e a organização amplia ainda mais sua legitimidade entre os presos, reforçando, consequentemente, seu status de garantidora de "paz entre os ladrões". ${ }^{1}$

Tratar de debates que equacionam políticas penais e práticas operadas por grupos criminosos originários dos cárceres é tocar em aspectos basilares ao respeito à dignidade da pessoa humana. Neste texto, avançamos nessa discussão a partir da análise das formas como Estado e PCC se interseccionam nas ações que levam à negação ou à materialização de dois direitos fortemente tensionados pela pandemia: o direito fundamental à vida, marcado no artigo $5^{\circ}$ da Constituição Federal, ${ }^{2}$ e o direito à saúde, listado no artigo 196. ${ }^{3}$

Para apresentar os resultados do estudo, indicamos inicialmente os passos dados no levantamento de dados. Em seguida, apresentamos uma revisão bibliográfica que conjuga as ideias de democracia, garantia de direitos e políticas penais comumente executadas no país. Ainda na revisão bibliográfica, apresentamos algumas discussões da literatura acadêmica acerca do PCC e de suas ações que acabam por se mesclar à atuação estatal. A partir de então, iniciamos a análise proposta neste artigo e introduzimos

\footnotetext{
1 Abordaremos esse lema mais à frente.

2 “Todos são iguais perante a lei, sem distinção de qualquer natureza, garantindo-se aos brasileiros e aos estrangeiros residentes no País a inviolabilidade do direito à vida, à liberdade, à igualdade, à segurança e à propriedade [...]" (BRASIL, 1988, art. $5^{\circ}$ ). 3 "A saúde é direito de todos e dever do Estado, garantido mediante políticas sociais e econômicas que visem à redução do risco de doença e de outros agravos e ao acesso universal e igualitário às ações e serviços para sua promoção, proteção e recuperação" (BRASIL, 1988, art. 196).
} 
Estado e PCC na pandemia: convergências e divergências na proposição de medidas de saúde... Thais Lemos Duarte $\bullet$ Natália Martino • Ana Beraldo

quais demandas têm sido efetuadas pelo grupo no cenário da Covid-19, conforme relatos da imprensa. Na seção seguinte, detalhamos as recomendações do $\mathrm{CNJ}$, comparando-as às diretrizes internacionais sobre as políticas sanitárias a serem tomadas em ambientes carcerários durante o cenário estabelecido pelo novo coronavírus. Por fim, apresentamos as convergências e as divergências entre as proposições do PCC e as medidas adotadas pelo Estado no enfrentamento à crise de saúde.

\section{Considerações metodológicas}

Parte dos dados aqui debatidos se baseia em um estudo de narrativas veiculadas pela imprensa sobre a ação do PCC em meio à crise causada pelo novo coronavírus. A escolha desse método se deveu à impossibilidade de realização de trabalho de campo em prisões decorrente justamente do contexto de pandemia e, mais importante, ao reconhecimento de que o uso de notícias de jornal como fonte de pesquisa social tem sido fundamental em trabalhos sociológicos voltados à compreensão das dinâmicas criminais e carcerárias (SALLA, 2015). Embora não seja nosso intuito aprofundar discussões relativas à mídia e à violência, sabemos que, para além de o conteúdo midiático facilitar interpretações de uma dada realidade como falsas ou verdadeiras, os jornais também orientam os atores sociais em suas rotinas (PORTO, 2009).

A pesquisa foi conduzida em duas fases. A primeira se centrou em um jornal de grande circulação, a Folha de São Paulo, reconhecido por publicar diversas matérias sobre o PCC, algumas das quais bastante minuciosas a respeito de seu modus operandi organizacional (DUARTE; ARAÚjO, 2020). O corte temporal da coleta se ateve entre o momento em que a Organização Mundial de Saúde (OMS) decretou a Covid-19 como pandemia de ordem mundial, em 11 de março de 2020, e o dia 31 de agosto de 2020, momento inicial de escrita deste artigo. 
Estado e PCC na pandemia: convergências e divergências na proposição de medidas de saúde... Thais Lemos Duarte $\bullet$ Natália Martino • Ana Beraldo

Inicialmente, utilizamos as palavras-chave "PCC" e "Primeiro Comando da Capital" no sistema de busca da Folha de São Paulo. A partir delas, chegou-se a 78 resultados, dentre matérias, notas e colunas de opinião. Muitos desses materiais indicavam prisões de integrantes da organização criminal, ou mesmo apenas citavam o PCC superficialmente. Ao conjugar ambas as palavras ao termo "pandemia", foram alcançadas 18 notícias, as quais foram lidas e analisadas, sendo o foco das reflexões aqui efetuadas.

Em uma segunda etapa, analisamos a Recomendação $n^{\circ} 62$ do Conselho Nacional de Justiça $(\mathrm{CNJ}),{ }_{1}^{4}$ sem nos furtarmos a contrastá-la com diretrizes internacionais lançadas pela Comissão Interamericana de Direitos Humanos, além de medidas emanadas pelo Subcomitê de Prevenção à Tortura e pelo Alto Comissariado, ambos das Nações Unidas. Todos esses dispositivos tiveram como objetivo regular as condições dos ambientes de privação de liberdade, bem como apontar caminhos para a garantia dos direitos à saúde e à vida das pessoas em julgamento ou julgadas pelos sistemas de justiça criminal no contexto da pandemia. Por fim, consideramos também um conjunto de dados públicos, como os divulgados pelo CNJ e pelo Departamento Penitenciário Nacional (DEPEN), a respeito do contexto carcerário brasileiro no quadro atual. Esses dados ajudaram a compreender até que ponto a Recomendação 62 do CNJ foi utilizada para balizar as decisões dos diversos tribunais de justiça do país.

Em suma, este trabalho conjuga um estudo documental, a partir das normativas e notícias de jornais, com uma análise descritiva de dados quantitativos fornecidos por fontes governamentais.

\section{Democracia, direitos e encarceramento no Brasil}

O Brasil tem passado por importantes transformações nas últimas décadas, construindo um cenário permeado por ambi-

4 Disponível em: https://www.cnj.jus.br/wp-content/uploads/2020/03/62-Recomenda\%C3\%A7\%C3\%A3o.pdf. Acesso em: 15 de setembro de 2020. 
Estado e PCC na pandemia: convergências e divergências na proposição de medidas de saúde... Thais Lemos Duarte $\bullet$ Natália Martino • Ana Beraldo

guidades diversas. Se, por um lado, o país viveu uma abertura política e uma ampliação do acesso a direitos em face do declínio da ditadura cívico-militar, por outro, vivenciou o crescimento da criminalidade e da violência, o punitivismo como forma de governo e a manutenção de intensos e persistentes abusos de agências de segurança pública (AZEVEDO, 2004; CALDEIRA; HOLSTON, 1999; FELTRAN, 2007; SANTANDER JOO et al., 2015).

Autores como Valente (2018) e Marques (2017) destacaram que, longe de ser um aspecto que "falhou" ao longo dos anos, a manutenção do caráter repressivo e bélico das forças de segurança brasileiras foi parte das negociações promovidas pela Assembleia Constituinte de 1987, ocupando espaço de relevância em todo o processo de redemocratização do país. A estrutura autoritária forjada sob o domínio dos militares foi, em grande medida, transplantada para as polícias (VALENTE, 2018), em um fomento da expansão do sistema penal do país (MARQUES, 2017). Com efeito, ao mesmo tempo em que o país dispõe de um leque significativo de normas voltadas à garantia das liberdades individuais, há o crescimento de instrumentos de controle repressivo (SALLA; BALLESTEROS, 2008), além de um reconhecido tratamento torturante destinado a grupos vulneráveis da população (PASTORAL CARCERÁRIA, 2016).

Baseadas na literatura e tendo em vista o foco da presente pesquisa, elencamos aqui sete tendências, três ligadas ao aprofundamento democrático e as demais ligadas à transformação do universo criminal, que se avultaram desde a redemocratização e compõem esse contexto de ambiguidades em que estamos imersos no país. ${ }^{5}$ Sobre o aprofundamento democrático: a) o crescimento da participação popular em espaços democráticos, seja através de eleições e referendos, seja através de movimentos sociais ou organizações da sociedade civil (SANTANDER JOO et al., 2015); b) um aumento dos investimentos governamentais em políticas de proteção social - ao menos até o processo de impeachment de Dilma Rousseff em 2016 (SANTANDER JOO et al., 2015);

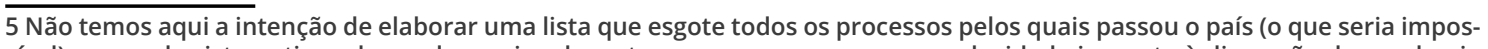
sível), mas a de sistematizar alguns dos mais relevantes para pensarmos na complexidade inerente à discussão da pandemia nos contextos prisionais brasileiros. 
Estado e PCC na pandemia: convergências e divergências na proposição de medidas de saúde... Thais Lemos Duarte $\bullet$ Natália Martino • Ana Beraldo

c) a redução da pobreza e do analfabetismo (SANTANDER JOO et al.,, 2015; PERLMAN, 2003).

Somados a esses, conjugou-se aquilo que Misse (1999, 2009) salientou poder ser compreendido como consequência de um processo de "acumulação social da violência" ${ }^{6}$ : a) um aumento dos índices de criminalidade, em especial dos delitos contra o patrimônio e dos crimes contra a vida, como homicídios dolosos (SOARES, 2003); b) a expansão do mercado de drogas, sobretudo com o advento da venda de cocaína, marcando um ponto de inflexão nas dinâmicas de funcionamento do mercado ilícito (LEEDS, 1996; MISSE, 1999; ZALUAR, 1994); c) a perpetuação de graves violações de direitos humanos (CALDEIRA, 2002); e d) a emergência de organizações criminais associadas ao tráfico de drogas, como o PCC (AMORIM, 2004; BIONDI, 2010, 2014; DIAS, 2011; SILVESTRE, 2016; FELTRAN, 2018; MARQUES, 2009, 2010; MANSO; DIAS, 2017, 2018).

Em consequência, ainda que formalmente seja sustentada a narrativa sobre o ideal de ressocialização dos custodiados, na prática, ficam cada vez mais arrefecidas as determinações que reforçam a função preventiva da sanção penal (GARLAND, 2008). ${ }^{7}$ Ganham força, assim, medidas de controle social rígido e políticas penais destinadas ao aprisionamento (SINHORETO et al., 2013). Esta vertente de ação estatal se fundamenta na perspectiva de que os riscos devem ser reduzidos, as políticas de prevenção ao crime devem ser amplas, bem como os criminosos devem ser severamente punidos e controlados (BAUMAN, 1999; WACQUANT, 1999). No entanto, essas ações não são desenvolvidas de modo homogêneo para todos os tipos de crimes e criminosos. A seletividade do sistema de justiça e o hiperencarceramento marcam o cotidiano penal do país (SINHORETTO; SILVESTRE; MELO, 2013).

\footnotetext{
6 Segundo Misse (1999), não seria possível esgotar a construção social do crime baseada unicamente na criminalização da conduta, tendo em conta os aspectos legais do comportamento individual. Nesse sentido, o autor propôs uma análise complexa do chamado processo de "acumulação social da violência", cujo efeito é gerar uma forte exclusão social do indivíduo que apresenta uma determinada classificação social em face do delito cometido e de sua condição social.

7 Conforme Bozza (2013), a pena dispõe de duas funções: a retribuição e a prevenção. O seu caráter retributivo se refere à compensação da culpabilidade. Ou seja, a sanção penal se constituiria como uma espécie de pagamento da violação de direito realizada pela pessoa que tenha cometido um crime, sendo uma forma de recompensa à sociedade pela falta cometida. Por sua vez, o caráter preventivo da pena é marcado por duas vertentes. Uma delas é a preventiva especial, cujo objetivo é reduzir a criminalidade, ora ressocializando o criminoso - prevenção especial positiva -, ora evitando que ele cometa mais crimes - prevenção especial negativa. A outra se refere à preventiva geral, cuja função é inibir a prática de crimes pelos demais membros da sociedade.
} 
Estado e PCC na pandemia: convergências e divergências na proposição de medidas de saúde... Thais Lemos Duarte $\bullet$ Natália Martino • Ana Beraldo

O endurecimento punitivo intensificado a partir da Lei de Drogas (11.343/2006) talvez seja o caso mais emblemático nesse sentido. Apesar de dispor de avanços formais no reconhecimento dos direitos dos usuários de drogas, a norma aumentou a pena mínima do delito de tráfico de entorpecentes de três para cinco anos, o que gerou incrementos significativos nos níveis de encarceramento no país (CARLOS, 2015). Para além do aumento formal da sanção punitiva, ao não definir objetivamente as diferenças entre uso e tráfico, a norma deixou para os operadores da Justiça a função de proceder essa distinção a partir das circunstâncias sociais do acusado e da prisão. Em especial, jovens, negros e pobres costumam ser mais vigiados através do policiamento ostensivo de determinadas áreas geográficas, em geral, dos espaços de periferia. Aumenta-se, pois, o número de flagrantes relativos a crimes cometidos por essas populações, sendo aguçada a marginalização a que já estavam submetidas antes do contato com o sistema de justiça (WILSON; SAMPSON, 1995; FORMAN, 2012). Nesse panorama, as polícias, o Judiciário e o Ministério Público atuam em uma intensificação do processo de criminalização de grupos sociais economicamente desfavorecidos e racialmente oprimidos, e pessoas que antes poderiam ser enquadradas como usuárias acabam condenadas como traficantes sob penas altas (GRILLO; POLICARPO; VERÍSSIMO, 2011).

\section{Condições carcerárias}

Os caminhos da pós-democratização no que tange às políticas penais fizeram com que a taxa de encarceramento subisse de 61 presos para grupos de 100.000 habitantes no país em 1990 para 366 custodiados para cada 100.000 brasileiros em 2019. ${ }^{8}$ Em outros termos, em menos de 30 anos, a população carcerária nacional cresceu seis vezes. Com efeito, em dezembro de 2019, o sistema penitenciário compreendia 748 mil pessoas privadas de

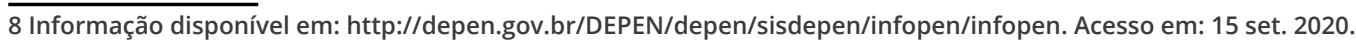


Estado e PCC na pandemia: convergências e divergências na proposição de medidas de saúde... Thais Lemos Duarte $\bullet$ Natália Martino • Ana Beraldo

liberdade, ${ }^{9}$ dentre as quais mais de $30 \%$ aguardavam sentença a ser emitida pelo juiz.

Esse universo de presos coloca o país, em números absolutos, atrás apenas dos Estados Unidos, cujo conjunto de detidos é superior a dois milhões de indivíduos, e da China, com um contingente superior a um milhão de custodiados. ${ }^{10}$ Em dezembro de 2019, o Acre era o estado que mais encarcerava, com 897 presos para cada 100.000 habitantes. Por sua vez, São Paulo ficava em quinto lugar no ranking nacional, com 506 custodiados para cada 100.000 habitantes, ao passo que a Bahia se colocava em último, com 105 presos para cada 100.000 habitantes (VELASCO; REIS, 2019). Em números absolutos, São Paulo, nascedouro do PCC, é o detentor da maior população prisional do país, com um total de 233.089 presos e uma taxa de ocupação de suas prisões de quase $160 \%{ }^{11}$

Algumas organizações da sociedade civil nacionais têm apontado periodicamente para as violações de direitos que acometem os estabelecimentos prisionais. Em seu relatório "Tortura em tempos de encarceramento em massa", a Pastoral Carcerária (2016) comparou as prisões brasileiras ao famoso cenário infernal narrado por Dante Alighieri, já que os cárceres são marcados por práticas regulares de tortura, não só através da violência física, mas também da violência psíquica cometida por agentes do Estado contra os presos e suas famílias.

\begin{abstract}
No inferno das prisões não existem placas, mas o condenado sabe que vai começar seu padecimento. Quando as grades se fecham, abre-se um mundo de violência, corrupção, superlotação, promiscuidade e descaso - muito descaso - por parte das autoridades públicas, famílias e sociedade. (PASTORAL CARCERÁRIA, 2016, p. 13)
\end{abstract}

\footnotetext{
9 Idem.

10 Informação disponível em:

https://www.prisonstudies.org/highest-to-lowest/prison-population-total?field_region_taxonomy_tid=All. Acesso em: 15 ago. 2020. 11 Informação disponível em: http://depen.gov.br/DEPEN/depen/sisdepen/infopen/infopen. Acesso em: 15 set. 2020.
} 
Estado e PCC na pandemia: convergências e divergências na proposição de medidas de saúde... Thais Lemos Duarte $\bullet$ Natália Martino • Ana Beraldo

Esses "padecimentos" se materializam também por meio da negação de atendimentos jurídicos e de saúde. Sobre este último ponto - fundamental para a discussão que propomos no presente texto -, destacam-se os ambientes insalubres dos cárceres brasileiros, com pouca iluminação e quase nenhuma ventilação, aliados à má alimentação e à falta de atendimento médico (PASTORAL CARCERÁRIA, 2016). Em consequência, doenças infecciosas costumam penalizar muito mais os custodiados do que os indivíduos em liberdade. Não à toa, o Ministério da Saúde apontou, em relatório publicado em 2017, que a incidência de tuberculose na população prisional chega a ser quase 30 vezes maior do que na população geral. ${ }^{12}$

Nesse mesmo sentido, Drake e Karam (2016) evidenciaram a omissão de Estados latino-americanos ao não fornecer aos seus custodiados itens básicos de sobrevivência, como sabonetes ou remédios. A responsabilidade de distribuir esses produtos aos presos recai, então, sobre seus familiares, onerando-os. Ao conjugarem tal tarefa ao cotidiano de visitas em unidades prisionais quase sempre distantes das regiões onde vivem, as famílias enfrentam dificuldades para garantir a continuidade dos vínculos afetivos (GODOI, 2015). Nesse cenário, muitos custodiados e seus parentes acabam à mercê de organizações criminais que ajudam a superar economicamente certos obstáculos. O PCC seria uma dessas organizações, fornecendo não apenas itens necessários à vida na prisão, mas também propiciando transporte aos visitantes para irem regularmente às unidades prisionais (GODOI, 2015).

Em outros termos, a gestão das políticas de segurança pública adotadas em território nacional tende a impactar grupos em condições sociais e econômicas vulneráveis, aprofundando desigualdades. A democracia é um valor ainda em consolidação no Brasil, e as condições carcerárias nacionais indicam que, pelo menos para algumas populações, o acesso a direitos não foi concretizado (SANTANDER JOO et al., 2015). Para tais indivíduos, que se veem a todo momento engajados em uma tentativa incessante

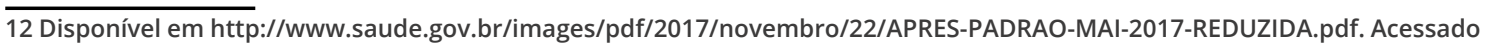
em: 16 set. 2020. 
Estado e PCC na pandemia: convergências e divergências na proposição de medidas de saúde... Thais Lemos Duarte $\bullet$ Natália Martino • Ana Beraldo

por "sobreviver na adversidade" (HIRATA, 2018), outros caminhos, não necessariamente legais, podem ser, muitas vezes, os que se apresentam em seus restritos e conflituosos horizontes de possibilidades. É nesse contexto que grupos como o PCC nascem, crescem e se constituem como interlocutores entre presos e Estado (BARBOSA, 2005; FELTRAN, 2018; DIAS, 2011; SILVESTRE, 2016; BIONDI, 2010, 2014), conforme trataremos mais detalhadamente na seção a seguir.

\section{Hiperencarceramento e PCC}

Adotar a política de encarceramento em massa, somada a violações sistemáticas de direitos, tem gerado impactos severos nas rotinas prisionais e nas trajetórias dos custodiados. Uma vez presos, esses indivíduos são submetidos a condições torturantes. E um dos caminhos possíveis na luta pela sobrevivência é o da formação de grupos de custodiados para organizar demandas e realizar ações coletivas de reivindicações. Essas ações transitam no limiar entre o legal e o ilegal, como destacou Góes (2009) em seu estudo sobre as rebeliões nos presídios paulistas na década de 1980. Já naquele momento, grupos de presos forjavam tréguas e alianças entre si na resistência contra ações policiais repressivas dentro das unidades (GÓES, 2009), o que, alguns anos depois, seria reinterpretado e ganharia novos significados e contornos com o surgimento do PCC.

Em 1992, o assassinato de 111 custodiados durante a repressão policial a uma rebelião na Casa de Detenção de São Paulo, popularmente conhecida como Carandiru, tornou evidente aos olhos da sociedade a realidade violenta característica do cotidiano penitenciário no Brasil (SILVESTRE, 2016). Autora do primeiro trabalho etnográfico de grande envergadura sobre o PCC, Biondi $(2010,2014)$ argumenta que, para os presos, o horror diante daquilo que ficou conhecido como "massacre do Carandiru" e da explicitação da profunda vulnerabilidade em que se encontravam 
Estado e PCC na pandemia: convergências e divergências na proposição de medidas de saúde... Thais Lemos Duarte $\bullet$ Natália Martino • Ana Beraldo

no interior do sistema carcerário serviu como fator determinante para o crescimento do sentimento de que era preciso investir em estratégias de autopreservação.

Biondi $(2010,2014)$ destaca também que foram duas as principais respostas estatais que se seguiram ao massacre. A primeira, como já introduzimos, se referiu à intensificação das políticas de aprisionamento. Ou seja, ao invés de promoverem medidas garantidoras de direitos, agentes e instituições estatais atuaram de forma a expandir vertiginosamente a população carcerária paulista. A segunda, ocorrida de forma concomitante à anterior, foi o esforço de descentralização do sistema penitenciário, cujo efeito foi o aumento do número de cárceres por diversas partes do estado de São Paulo. Como consequência, cresciam, simultaneamente, a população prisional estadual e as violações típicas do ambiente prisional, como a tortura, com o diferencial de tais práticas passarem, agora, ainda mais ao largo do controle social (DIAS, 2011; FELTRAN, 2018; SILVESTRE, 2016). ${ }^{13}$

No ano de 1993, menos de um ano depois da tragédia do Carandiru, durante uma rebelião no Centro de Reabilitação Penitenciária, anexo à Casa de Custódia e Tratamento de Taubaté, em São Paulo, o PCC começou a tomar forma como uma organização que visava à proteção entre os presos e o "combate à opressão carcerária" (DIAS, 2011; FELTRAN, 2018; BIONDI, 2010, 2014).14 O grupo reivindicava o enfrentamento às injustiças por meio da ideia de "paz entre os ladrões, e guerra contra o sistema" (BIONDI, 2010, 2014; DIAS, 2011; FELTRAN, 2018; MARQUES, 2010, 2016). As pessoas custodiadas se uniram contra um inimigo comum, especialmente personificado em agentes de controle do Estado, como a polícia e a administração prisional (FELTRAN, 2018). Com o uso de meios violentos, mas também pelo convencimento e pela pretensa justeza com que aplicava essa violência, o coletivo ingressou inicialmente em uma etapa de embate com outros grupos no

\footnotetext{
13 Pelo fato de que as prisões estão mais distantes dos familiares dos custodiados e dos órgãos de fiscalização. 14 A história de fundação do PCC pode ser encontrada em alguns livros escrito por jornalistas, dentre outros, Jozino (2005).
} 
Estado e PCC na pandemia: convergências e divergências na proposição de medidas de saúde... Thais Lemos Duarte $\bullet$ Natália Martino • Ana Beraldo

interior das prisões e conseguiu, ao longo dos anos, tornar-se o principal ator no universo carcerário paulista (FELTRAN, 2012).

Reconfiguravam-se, portanto, as hierarquias e as relações sociais dentro dos muros. Dias (2011) aponta para duas facetas primordiais dessas mudanças, ambas relacionadas à capacidade que o PCC desenvolveu de acesso às "oportunidades de poder" do universo prisional: a conquista do monopólio mercadológico, com o domínio dos comércios legais e ilegais presentes nas instituições penais; e a obtenção do monopólio do uso da força, com uma regulação dos instrumentos de violência (como facas ou canivetes, até então comuns nas cadeias, por exemplo), que passam a ser exclusividade de membros do "partido".

Com o passar dos anos e com o enorme contingente de egressos do sistema prisional decorrente do encarceramento massivo (SINHORETTO et al., 2013), o PCC - cujo acesso a recursos letais era nada desprezível - passou a atuar também nas periferias urbanas, em um processo que teve como maior marco os enfrentamentos entre a organização e a Polícia Militar de São Paulo, ocorridos em 2006. Em um intervalo de uma semana, foram assassinadas 493 pessoas em São Paulo, entre agentes do estado e população civil (CANO; ALVADIA, 2008; FELTRAN, 2012). Deste ano em diante, houve uma progressiva estabilização do cenário, e o PCC se consagrou como importante ator nas relações de poder não só no sistema prisional, mas também nas periferias paulistas, se consolidando como uma nova figura social hegemônica dentro e fora dos cárceres (ADORNO; DIAS, 2016).

O PCC passou a deter grande parte da regulação do varejo de drogas, dos roubos, da violência e dos comportamentos dos moradores de bairros pauperizados, mesclando em sua prática cotidiana o uso da força com oferta de garantias costumeiramente negadas pelo Estado aos que vivem sob seu domínio (BIONDI, 2014). Entre outras ações, o grupo fornece cestas básicas aos desempregados e atendimento jurídico à população carcerária, alimentando a retórica de "paz entre os irmãos" e de luta contra injustiças (FELTRAN, 2018). Nota-se que, nessa dinâmica, o “ini- 
Estado e PCC na pandemia: convergências e divergências na proposição de medidas de saúde... Thais Lemos Duarte $\bullet$ Natália Martino • Ana Beraldo

migo" já não está mais circunscrito à "opressão carcerária", mas se expande e passa a abarcar os muitos processos de exclusão a que estão submetidos os pobres urbanos (setores da população que são alvo preferencial das políticas de encarceramento), desde as dificuldades em conseguirem ingressar no mercado de trabaIho, passando pela violência policial e pelo preconceito advindo das classes mais abastadas. Contra isso tudo se posiciona o PCC, muitas vezes chamado simplesmente de "crime" (MARQUES, 2009, 2010, 2016).

De fato, o PCC instituiu formas mais racionais de atuação, com execuções planejadas, decorrentes de circunstâncias e motivações específicas (BIONDI, 2014; MARQUES, 2009). Biondi (2014), Willis (2015) e Feltran $(2010,2013)$ apontaram que, para além da regulação das regras do cotidiano prisional, o grupo passou a disputar espaço de legitimação nas sociabilidades periféricas, tornando-se uma instância de justiça. A principal medida nesse sentido foi a extrapolação da reivindicação do monopólio do uso da força pelo grupo, que já estava em vigor nos cárceres e que passou a avançar também para os territórios empobrecidos das cidades. O PCC estabeleceu, entre os setores pobres paulistas dentro e fora das grades, a necessidade da "autorização para matar", em uma espécie de "política de paz", efetivada através do popularmente chamado "tribunal do crime". Os conflitos passaram a ser resolvidos por julgamentos informais conduzidos pelo PCC em que são apresentadas a acusação, a defesa, bem como é proferida e executada a sentença. Com isso, os homicídios retaliatórios ou motivados por desentendimentos relativamente banais são suprimidos, ocasionando uma substantiva redução nas taxas de mortes violentas no estado de São Paulo (FELTRAN, 2010; WILLIS, 2015).

Após mais de 25 anos de existência, a organização é frequentemente alvo de interesse da imprensa e de outros atores públicos, sendo hoje retratada como o maior grupo criminal do país (DUARTE; ARAÚJO, 2020). Segundo o Ministério Público paulista, o PCC disporia de cerca de 30.000 integrantes espalhados em todas as unidades da federação e em alguns países vizinhos, como 
Estado e PCC na pandemia: convergências e divergências na proposição de medidas de saúde... Thais Lemos Duarte $\bullet$ Natália Martino • Ana Beraldo

Bolívia e Paraguai (DUARTE, 2020). Estes sujeitos estariam divididos em espécies de células autônomas, as chamadas "sintonias", cujo objetivo final seria a ampliação de novos mercados e, por sua vez, a dilatação da capacidade lucrativa organizacional. É interessante notar o fascínio que o grupo parece suscitar, bem como as perspectivas quase ficcionais que perpassam os discursos acerca de sua atuação (MINGARDI, 2007), especialmente por parte de atores que formam o poder público.

Ainda que existam representações bastante fantasiosas sobre o PCC, é importante ressaltar a natureza idiossincrática que de fato caracteriza a organização (MANSO; DIAS, 2018; FELTRAN, 2018; BIONDI, 2010, 2014). No âmbito econômico, alguns integrantes do grupo podem até apresentar um perfil empresarial e bélico. Contudo, com características de "sociedade secreta", o PCC se constitui principalmente como um agente de regulação mercantil (FELTRAN, 2018). Sua proposta é agir discretamente, distante de um modelo de guerra pública, de terror e de estrutura piramidal. Procede, então, como irmandade. Garantindo a ordem nas cadeias e nas periferias, o PCC reduziria não apenas os conflitos internos ao crime, mas também com as polícias e o governo, fortalecendo-se junto à população pobre da cidade (FELTRAN, 2018). Alguns autores, principalmente os que trabalham em pesquisas com enfoque nas significações, valorações e linguagens internas ao universo criminal (AQUINO; HIRATA, 2018; BARBOSA, 2016), têm argumentado que o PCC, mais do que um representante do "crime organizado", pode ser interpretado como uma experiência política (DIAS, 2011; BIONDI, 2010; FELTRAN, 2013).

Tendo o PCC essas características, a organização ganha proeminência, especialmente em tempos de crise social, como a produzida em decorrência da pandemia do novo coronavírus. $\mathrm{Na}$ seção a seguir, aprofundaremos esse debate. 


\section{PCC e suas demandas em tempos de pandemia}

Nosso esforço nesta e na próxima seção é discutir as narrativas da imprensa sobre a ação do PCC durante a pandemia, bem como compreender a ação estatal no campo prisional em face da crise de saúde. Partimos da ideia debatida por Prando et al. (2020) de que são propostos dois tipos de relatos sobre a questão. Por um lado, produz-se a imagem de um Estado eficiente, preocupado em garantir direitos e preservar a segurança pública, alinhando, então, políticas penais com as de saúde. Por outro, são reforçadas representações sociais do medo e da periculosidade para legitimar a imagem de um Estado intransigente e purificador.

Esse modo de operar se aproxima do que Leite (2012) chama de "metáfora da guerra", isto é, a representação socialmente compartilhada de contextos urbanos como cenários de "guerra", em que setores inimigos se enfrentariam em combates marcados pelo uso da força. De um lado, estariam os "bandidos", especialmente os "traficantes de drogas", e, de outro, o Estado ou a polícia. Gestada a partir de episódios violentos como tiroteios, "balas perdidas", chacinas e rebeliões em presídios, e reforçada por narrativas sensacionalistas veiculadas pela imprensa, essa representação mobiliza um forte sentimento de insegurança entre grupos sociais. A população é, então, chamada a escolher um dos lados, legitimando-se uma perspectiva em que a segurança pública é tida como protetora de parte da sociedade (os "cidadãos de bem" das classes médias e altas, principalmente) contra a ameaça representada por outro segmento da população (os "bandidos" em especial, mas isso também acaba por incluir as "classes perigosas", os "favelados" de maneira geral).

Nesse mesmo sentido, a representação fortemente difundida por atores públicos sobre o PCC como um inimigo articulado, violento e ameaçador, se dominante em tempos de "normalidade", também se faz presente de maneira fundamental no contexto da Covid-19. Em meio a uma narrativa que na maioria das vezes pareceu incitar o "temor", sob o risco de ser instaurado um "caos 
Estado e PCC na pandemia: convergências e divergências na proposição de medidas de saúde... Thais Lemos Duarte $\bullet$ Natália Martino • Ana Beraldo

na segurança pública", é possível dizer, resumidamente, que a Folha de São Paulo sinalizou para três tipos centrais de demandas do PCC durante a crise de saúde, reveladas entre motins, fugas de presos e rebeliões: a) regularização das visitas familiares aos cárceres; b) liberação de presos idosos e/ou com comorbidades, sujeitos a maiores riscos de agravamento no caso de infecção pelo novo coronavírus; e c) retorno da aplicação das saídas temporárias aos custodiados em regime semiaberto, popularmente conhecidas como "saidinhas". ${ }^{15}$

O que parece ter ocorrido é um rápido escalonamento da conflituosidade nas prisões. Em meados de março, logo após a Organização Mundial de Saúde (OMS) decretar estado de pandemia em razão do novo coronavírus, relatou-se na Folha de São Paulo que presos do PCC fugiram e realizaram "atos de insubordinação" em unidades prisionais paulistas (RODRIGUES et al., 2020). A tensão nas prisões se iniciou após a proibição das visitas em alguns estabelecimentos, o que costuma ocasionar forte impacto no ambiente prisional, mesmo em contexto de dita "normalidade". Silvestre (2012) ressalta o quanto as famílias de presos, em especial as companheiras e as esposas, são essenciais para manter os cárceres "pacíficos". Esses atores constituem fontes de afeto, ajudam a estabelecer canais de comunicação entre o fora e o dentro da prisão, trazem alimentos e outros materiais de uso pessoal aos presos, além de, em certas ocasiões, adotarem posições estratégicas na execução de determinados ilegalismos no ambiente prisional e em espaços de periferias urbanas (SILVESTRE, 2012; PADOVANI, 2015). Quando as visitas são raras no cárcere, o que costuma ocorrer em especial em prisões femininas, abre-se margem à barganha entre pessoas privadas de liberdade e ao desenvolvimento de relações assimétricas (PADOVANI, 2015).

O cenário de tensionamento carcerário se agravou ainda mais com a suspensão pela Justiça das audiências nos fóruns e das "saidinhas" temporárias. Essas medidas foram adotadas pelo poder público sob a justificativa de se evitar a circulação do vírus de fora para dentro das prisões, ignorando-se nesse aspecto que, além

15 Períodos de sete dias fora dos cárceres garantidos aos custodiados em regime semiaberto. 
Estado e PCC na pandemia: convergências e divergências na proposição de medidas de saúde... Thais Lemos Duarte $\bullet$ Natália Martino • Ana Beraldo

dos custodiados e seus familiares, outros indivíduos, como os funcionários, saem e entram todos os dias dos estabelecimentos penais.

\begin{abstract}
A medida foi necessária pois o benefício [de saída temporária] contemplaria mais de 34 mil sentenciados do regime semiaberto que, retornando ao cárcere, teriam elevado potencial para instalar e propagar o coronavírus em uma população vulnerável, gerando riscos à saúde de servidores e de custodiados. A SAP [Secretaria de Administração Penitenciária de São Paulo] ainda realiza a contagem para determinar o número exato de fugitivos", diz, em nota [o chefe do Executivo] (RODRIGUES; PAGNAN; PAULUZE, 2020, s. p., acréscimo nosso).
\end{abstract}

Outra matéria indicou que integrantes da organização estariam acionando seus advogados para que fosse impetrado habeas corpus a todos os membros do grupo idosos ou que estivessem acometidos por doenças crônicas, como, por exemplo, diabetes e problemas cardiovasculares (ADORNO, 2020). Na ótica do PCC, esse conjunto de custodiados deveria ser liberado com urgência, já que os cárceres estão superlotados, apresentam péssimas condições infraestruturais e não oferecem adequada assistência à saúde. Essas circunstâncias poderiam não só potencializar a propagação do novo coronavírus, como também colocariam em risco a vida de muitos presos.

Noticiou-se, nesse bojo, a concessão da prisão domiciliar a um suposto "chefe" do PCC que sofre de hipertensão. Por ser considerado principal aliado das lideranças "mais violentas da facção", o governo buscou reverter a decisão (PAGNAN, 2020).

Aliado de integrantes da cúpula, tidos como os mais violentos da facção, segundo a polícia, como Roberto Soriano, o Tiriça, e Daniel Canônico, o cego (ambos no sistema federal), Batatinha ficará em casa sem vigilância externa nem com tornozeleira eletrônica de vigilância. De acordo com o juiz Adjair de Andrade Cintra, do Deecrim (Unidade Regional de Departamento Estadual de 
Estado e PCC na pandemia: convergências e divergências na proposição de medidas de saúde... Thais Lemos Duarte $\bullet$ Natália Martino • Ana Beraldo

Execução Criminal), Lima é hipertenso e, assim, ele se enquadra no grupo de pessoas mais vulneráveis à Covid-19 e, por isso, corre risco de morte se continuar no sistema penitenciário. (PAGNAN, 2020, s. p.).

O trecho acima é revelador, já que demonstra certo espanto da imprensa a respeito da soltura da liderança do PCC e, especialmente, de essa liberação estar associada a uma autorização judicial para cumprir prisão domiciliar sem estar submetida a qualquer forma de controle, como a monitoração eletrônica, por exemplo. Em boa medida, essa narrativa da Folha de São Paulo vai ao encontro de perspectivas ventiladas por certos setores do poder público sobre o tratamento a ser conferido às pessoas privadas de liberdade durante a pandemia. Entretanto, contraria a Recomendação 62 do CNJ e outras diretrizes emanadas por órgãos internacionais de direitos humanos. Na seção a seguir, analisaremos essa recomendação e as diretrizes com as quais ela converge.

\section{2}

\section{Recomendações aos atores do sistema de Justiça}

Atentos aos níveis e às condições de encarceramento de certos países, logo após a OMS reconhecer a Covid-19 como pandemia, órgãos como o Subcomitê de Prevenção à Tortura e o Alto Comissariado, ${ }^{16}$ ambos das Nações Unidas, assim como a Comissão Interamericana de Direitos Humanos, ${ }^{17}$ propuseram que os governos adotassem algumas medidas urgentes, a fim de evitar que o novo coronavírus causasse danos graves em unidades de privação de liberdade. Conforme tais atores, os riscos representados pelo vírus nos cárceres, no que tange à transmissão e ao dano, são muito maiores em comparação aos efeitos causados na população em geral. A proximidade das pessoas presas em face da superlotação,

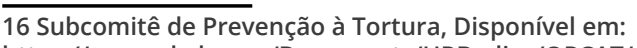

https://www.ohchr.org/Documents/HRBodies/OPCAT/AdviceStatePartiesCoronavirusPandemic2020.pdf. Acesso em: 15 set. 2020. Alto Comissariado, Disponível em: http://www.oacnudh.org/covid-19-se-necesitan-medidas-para-proteger-a-las-personas-privadas-de-libertad-expertos-onu/. Acesso em: 15 set. 2020

17 Disponível em: https://www.oas.org/es/cidh/prensa/comunicados/2020/066.asp. Acesso em: 15 set. 2020. 
Estado e PCC na pandemia: convergências e divergências na proposição de medidas de saúde... Thais Lemos Duarte $\bullet$ Natália Martino • Ana Beraldo

as parcas possibilidades de distanciamento social, a má alimentação, a falta de remédios e de materiais de higiene, assim como os problemas de ventilação e higiene nos estabelecimentos penais, fomentam a propagação da doença.

Por conseguinte, com base em normativas internacionais de direitos humanos, ${ }^{18}$ os entes propuseram algumas recomendações aos estados. A maioria tem como objetivo diminuir os níveis de encarceramento e a alta ocupação carcerária, como sistematizado na tabela a seguir:

\section{Tabela 1: Resumo das recomendações internacionais de direitos humanos}

\begin{tabular}{l|l|l}
\hline 1. & \multicolumn{1}{|c}{ Recomendação } & \multicolumn{1}{|c}{ Público-alvo } \\
\hline 1. & $\begin{array}{l}\text { Garantia de assistência especializada e } \\
\text { particularizada à saúde; }\end{array}$ & $\begin{array}{l}\text { Indivíduos dos grupos de risco da } \\
\text { a) Pessoas idosas; } \\
\text { b) Mulheres grávidas e lactantes; } \\
\text { c) Presos com enfermidades crônicas } \\
\text { etc. }\end{array}$ \\
\hline 2. & $\begin{array}{l}\text { Adoção de medidas que possam gerar a } \\
\text { liberdade de pessoas com condições de saúde } \\
\text { vulneráveis; }\end{array}$ & $\begin{array}{l}\text { a) Indivíduos que cometeram delitos } \\
\text { não violentos ou menos graves; } \\
\text { b) Réus/condenados primários. }\end{array}$ \\
\hline 3. & $\begin{array}{l}\text { Garantir a liberação antecipada ou provisória, } \\
\text { através de prisão domiciliar ou outras medidas } \\
\text { não privativas de liberdade; }\end{array}$ & $\begin{array}{l}\text { Pessoas em cumprimento de penas } \\
\text { em regime semiaberto e aberto. }\end{array}$ \\
\hline 4. & $\begin{array}{l}\text { Garantia aos presos de igual tratamento de } \\
\text { saúde, com a mesma qualidade em relação a } \\
\text { um indivíduo em liberdade, sem discriminação } \\
\text { em razão de seu estado legal; }\end{array}$ & Pessoas custodiadas pelo Estado. \\
\hline 5. & $\begin{array}{l}\text { Garantia de acesso aos custodiados a materiais } \\
\text { de higiene pessoal, seja através da distribuição } \\
\text { sistemática de materiais pelo Estado ou pela } \\
\text { entrega de produtos remetidos por familiares; }\end{array}$ & Pessoas custodiadas pelo Estado. \\
\hline 6. & $\begin{array}{l}\text { Criação e, quando existentes, fortalecimento } \\
\text { dos mecanismos de reclamações e queixas de } \\
\text { violações de direitos. }\end{array}$ & $\begin{array}{l}\text { Todas as pessoas relacionadas ao } \\
\text { âmbito carcerário. }\end{array}$ \\
\hline
\end{tabular}

Fonte: Elaboração própria, com base em diretrizes internacionais de direitos humanos.

18 Como as Regras de Bangkok, as Regras de Mandela, as Regras de Tóquio e os Princípios e Diretrizes da ONU sobre o Acesso à Assistência Jurídica nos Sistemas de Justiça Penal. 
Estado e PCC na pandemia: convergências e divergências na proposição de medidas de saúde... Thais Lemos Duarte $\bullet$ Natália Martino • Ana Beraldo

A Recomendação $n^{\circ} 62$ do CNJ seguiu a mesma lógica dessas organizações e estipulou uma série de diretrizes às administrações prisionais e aos tribunais de justiça estaduais. Em resumo, a recomendação indica que sejam criados planos de contingências nos estabelecimentos penais e que seja reduzida a superlotação das unidades prisionais. Especificamente sobre este segundo ponto, entre outros aspectos, recomendou-se:

Tabela 2: Resumo das recomendações emanadas pelo CNJ

\begin{tabular}{l|l|l}
\hline & \multicolumn{1}{|c}{ Recomendação } & \multicolumn{1}{|c}{ Público-alvo } \\
\hline 1. & $\begin{array}{l}\text { Reavaliação das prisões provisórias, com } \\
\text { aplicação de prisão domiciliar e/ou monitoração } \\
\text { eletrônica; }\end{array}$ & $\begin{array}{l}\text { a) Gestantes, lactantes e/ou mulheres } \\
\text { responsáveis por crianças até 12 anos } \\
\text { de idade, entre outros grupos de } \\
\text { indivíduos vulneráveis; } \\
\text { b) Custodiados em estabelecimentos } \\
\text { superlotados, sem atendimento de } \\
\text { saúde adequado; } \\
\text { c) Presos em regime aberto e } \\
\text { semiaberto; } \\
\text { d) Presos preventivamente há mais de } \\
\text { 90 dias; } \\
\text { e) Pessoas que cometeram crime sem } \\
\text { violência ou grave ameaça. }\end{array}$ \\
\hline 2. & $\begin{array}{l}\text { Concessão de saída antecipada ao regime } \\
\text { semiaberto; }\end{array}$ & $\begin{array}{l}\text { Pessoas de grupos vulneráveis que } \\
\text { estejam em regime fechado. }\end{array}$ \\
\hline 3. & Aplicação de prisão domiciliar; & $\begin{array}{l}\text { Pessoas no regime semiaberto e } \\
\text { aberto. }\end{array}$ \\
\hline 4. & Relaxamento da prisão ilegal. & \begin{tabular}{l} 
Presos provisórios. \\
\hline
\end{tabular}
\end{tabular}

Fonte: Elaboração própria, com base na Recomendação nº 62 do CNJ.

Cabe destacar, ainda, que o CNJ não anteviu a suspensão das visitas familiares, tampouco esse tipo de medida foi previsto pelos órgãos internacionais. Ao contrário, indicou-se que fossem desenvolvidas ações voltadas à garantia de saúde dos visitantes e dos presos, bem como ao asseio dos espaços onde os encontros familiares costumam ser realizados nos cárceres. Entretanto, confor- 
Estado e PCC na pandemia: convergências e divergências na proposição de medidas de saúde... Thais Lemos Duarte $\bullet$ Natália Martino • Ana Beraldo

me o Departamento Penitenciário Nacional (DEPEN), de todas as unidades da federação, 17 suspenderam por completo as visitas familiares desde o início da pandemia, incluindo São Paulo, o que gerou revolta entre presos, como narrado na seção anterior. Já 10 estados mantiveram os encontros nos cárceres com restrições. ${ }^{19}$

De fato, o CNJ tem apontado para o parco efeito da sua recomendação nos sistemas de justiça criminais de distintas localidades. Entre março e maio de 2020, somente 35 mil pessoas foram liberadas de unidades prisionais para cumprirem prisão domiciliar e/ou se submeterem à monitoração eletrônica. Esse número corresponde a uma taxa de apenas $4,6 \%$ do total de pessoas em privação de liberdade, excluídas as em regime aberto e os presos em delegacias. Ou seja, um contingente baixo em um país onde a taxa de superlotação gira em torno de 170\%, de acordo com o DEPEN. ${ }^{20}$ Apesar de não terem sido disponibilizados dados específicos sobre a liberação de presos em São Paulo, é possível destacar que o número geral de solturas especificado pelo CNJ certamente não conseguiu reverter os problemas causados pelo enorme contingente carcerário estadual, submetido a forte superlotação.

A resistência em liberar grupos de presos pode ser interpretada como resultado de ações fomentadas pelos níveis mais altos do Poder Executivo, com impacto direto no trabalho dos operadores do direito. Em abril de 2020 foi publicada uma reportagem a respeito de uma "ofensiva" do então ministro da Justiça e Segurança Pública, Sergio Moro, contra a soltura de custodiados em razão da pandemia. E, como quase sempre é abordado em discussões dessa natureza (DUARTE; ARAÚJO, 2020), o PCC foi retratado na matéria como um grave problema social. Tal como disposto na notícia já analisada, relativa à soltura de uma liderança organizacional, pontuou-se que vários integrantes do grupo poderiam ser beneficiados com medidas de liberação, o que geraria insegurança à população. "A questão opõe Moro ao CNJ (Conselho Nacional de Justiça), que recomenda o habeas corpus temporário a pessoas

19 Informação disponível em: https://app.powerbi.com/view?r=eyjrljoiYThhMjk5YjgtZWQwYS00ODIkLTg4NDgtZTFhMTgzYmQ2MGVIliwidCI6ImViMD kwNDIwLTQ0NGMtNDNmNy05MWYyLTRiOGRhNmJmZThIMSJ9. Acesso em: 15 set. 2020. 20 Idem. 
Estado e PCC na pandemia: convergências e divergências na proposição de medidas de saúde... Thais Lemos Duarte $\bullet$ Natália Martino • Ana Beraldo

que fazem parte de grupos de risco da Covid-19, como portadores do HIV e idosos" (GIELOW, 2020, s. p.).

Essa mesma reportagem também advertiu que, embora o Poder Executivo paulista faça oposição pública ao governo federal, ambos estavam alinhados no enfrentamento às ações do dito "crime organizado" em cenário de pandemia. "Em São Paulo, centro nervoso do sistema e berço do PCC (Primeiro Comando da Capital), os órgãos de segurança estão de prontidão" (idem). Inclusive, a Folha de São Paulo apontou que tal mote de ação tinha ganhado forte apoio popular, manifestado, segundo a matéria, na aprovação positiva conferida a Moro como ministro da Justiça e Segurança Pública. Não à toa, durante a coletiva de imprensa em que se demitiu do cargo, como forma de prestação de contas das tarefas desempenhadas, ele revelou que:

Nós atuamos muito próximos das forças de segurança estaduais, até mesmo municipais. Nós realmente trabalhamos duro contra a criminalidade organizada. Ouso aqui dizer, claro que tudo isso é sujeito a críticas e segundas opiniões, mas que não houve um combate tão efetivo à criminalidade organizada como houve durante essa gestão do Ministério da Justiça e Segurança Pública. Trabalhando não contra, mas com os governos estaduais. Tivemos o caso, por exemplo, da transferência e isolamento das lideranças do PCC. Tivemos recentemente a prisão da maior autoridade do PCC em liberdade, 20 anos foragido, graças a um trabalho de investigação eficiente da Polícia Federal. (LEIA..., 2020, s. p.).

Em outros termos, o combate ao "crime organizado", em boa medida personificado no PCC, é uma ação considerada prioritária por atores dos poderes executivos federal e do estado de São Paulo. E, apesar de a literatura da área salientar as más condições prisionais e a negação de direitos a grupos marginalizados como alguns dos fatores que propiciaram o nascimento e o crescimento do PCC, certos segmentos do poder público buscam combater o 
Estado e PCC na pandemia: convergências e divergências na proposição de medidas de saúde... Thais Lemos Duarte $\bullet$ Natália Martino • Ana Beraldo

grupo acentuando essas mesmas violações. A narrativa do medo, amplamente divulgada pelos jornais, reduz a compreensão popular do que está em jogo na Recomendação 62, criando ambiente favorável para que os atores do sistema judiciário relutem em soltar os custodiados de forma a garantir seus direitos à saúde e à vida. O resultado se reflete nos baixos índices de solturas registrados pelo CNJ e no fortalecimento, junto aos grupos marginalizados, da narrativa do PCC como seu defensor contra as injustiças.

Diante da resistência em seguir a Recomendação 62, o que se observou foi o avanço da Covid-19 nas prisões. Segundo o CNJ (2020), entre 8 de abril - data da confirmação do primeiro caso de pessoa presa infectada - e 31 de agosto - data limite para as análises aqui desenvolvidas -, o número de presos infectados pelo novo coronavírus passou de dois para 20.879 custodiados, conforme evolução apresentada no Gráfico 1. Entre servidores do sistema prisional, o crescimento também foi intenso, saindo de um caso em 2 de abril de 2020 para 8.524 em 31 de agosto de 2020. Nesse mesmo intervalo de tempo, o número de óbitos por Covid-19 entre pessoas privadas de liberdade passou de dois para 104. Entre servidores do sistema prisional, avançou de dois para 79, totalizando 183 mortos. 
Estado e PCC na pandemia: convergências e divergências na proposição de medidas de saúde... Thais Lemos Duarte $\bullet$ Natália Martino • Ana Beraldo

\section{Gráfico 1: Evolução de presos infectados por Covid-19 nas prisões nacionais (abril a agosto de 2020)}

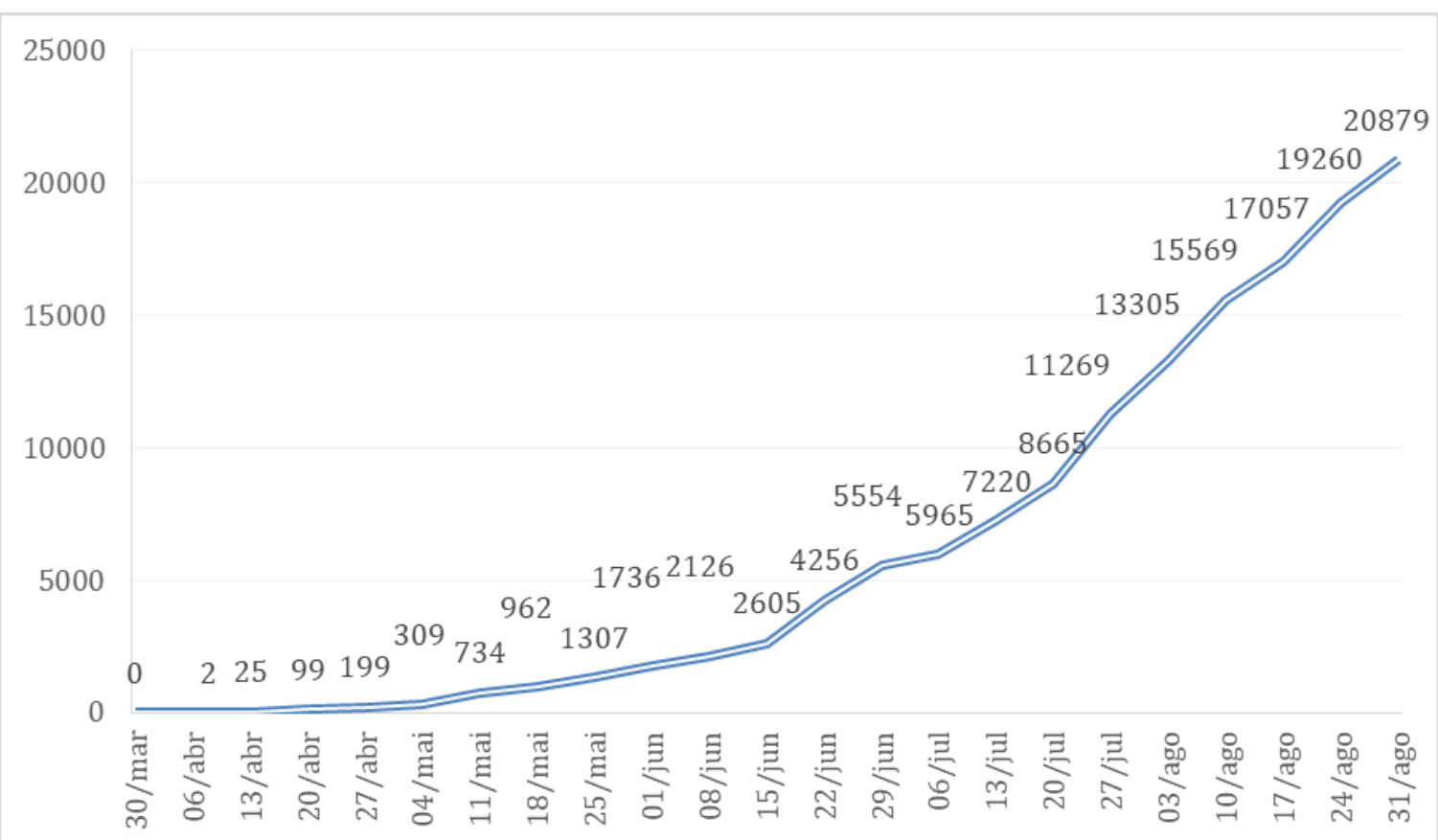

Fonte: CNJ - (2020).

\section{8}

Somente em São Paulo, entre março e 31 de agosto, foram confirmados 4.724 presos e 1.366 servidores infectados por Covid-19. Esses dados parecem até tímidos frente ao amplo universo de pessoas privadas de liberdade no estado. No entanto, em diálogo a essa observação, o CNJ também ressaltou o forte quadro de subnotificação a respeito da pandemia nas prisões, além de outros pesquisadores já terem chamado a atenção à questão (PRANDO et al., 2020).

Sabendo que o Brasil é um dos países do mundo onde menos são feitos testes entre os diferentes grupos populacionais, é provável que as somas de pessoas infectadas e mortas sejam, na verdade, muito maiores do que as indicadas pelas estatísticas oficiais. O cenário pode ser ainda mais dramático dentro das prisões, onde se sobrepõem uma estrutura facilitadora da propagação do vírus, um acesso precário à saúde e, por consequência, um déficit ainda maior de testagem. Em verdade, talvez nunca conheçamos 
Estado e PCC na pandemia: convergências e divergências na proposição de medidas de saúde... Thais Lemos Duarte $\bullet$ Natália Martino • Ana Beraldo

efetivamente os resultados de todo esse quadro, já que o controle social do sistema prisional, se já escasso em condições de "normalidade", torna-se quase inexistente com a suspensão das visitas familiares observada na maioria dos estados.

\section{“Nós" contra "eles"?}

Há muito, Adorno (1991) indicou que toda ação governamental que tenta incidir sobre o sistema carcerário precisa considerar a presença de organizações criminais. Isto é, iniciativas públicas de qualquer ordem não podem ignorar as forças que disputam a formulação de políticas prisionais e as tensões enfrentadas no exercício do controle sobre a massa carcerária. No limite, certos atores criminais gerariam modelos de cultura organizacional, dispondo de papel fundamental no fracasso e no sucesso de determinadas medidas estabelecidas.

Não se trata aqui de dizer que atores estatais de altos cargos devem legitimar a ação de grupos criminosos, tratando-os como sujeitos com papel formal no processo de formulação de políticas. Neste ponto, a crítica de Elio Gaspari, apontada na introdução deste artigo, pode ser considerada como válida. No entanto, vale questionar se o Estado legitima as ações criminais a partir de declarações como as do então ministro Luiz Henrique Mandetta ou se essa legitimação acontece como efeito de uma negação sistemática de direitos a populações empobrecidas, contexto parcialmente suprido por grupos criminosos.

Em outras palavras, os dados apresentados neste texto apontam para uma violação dos direitos à saúde e à vida de pessoas custodiadas em meio à pandemia. De igual maneira, desvela também a conformação de um cenário de tensão, no qual o PCC assume mais uma vez - como faz historicamente ao longo de toda sua trajetória - um papel de defensor dos presos. Em grande medida, ocorre, pois, uma validação, ainda que não planejada, do discurso de "paz entre os irmãos e guerra contra o sistema" que paira entre 
Estado e PCC na pandemia: convergências e divergências na proposição de medidas de saúde... Thais Lemos Duarte $\bullet$ Natália Martino • Ana Beraldo

os custodiados, suas famílias e suas comunidades (FELTRAN, 2018; DIAS, 2011; BIONDI, 2010, 2014).

Em consequência, em meio a tantos discursos e disputas, as demandas de organizações criminais em alguns momentos coincidem com normas legais do Estado desrespeitadas no cotidiano dos cárceres e das periferias. Isto nos leva a duas constatações. A primeira é a de que as exigências proferidas por grupos de presos devem ser escutadas e consideradas na formulação e na execução de políticas públicas prisionais. Ou seja, para dificultar que organizações como PCC se transformem em emissários centrais dos pedidos dos custodiados, cada vez mais se faz necessário o fortalecimento de canais formais de denúncia do Estado, como as ouvidorias dos sistemas prisionais, os mecanismos de prevenção à tortura e a Defensoria Pública. Não à toa, organizações internacionais recomendaram a criação e o reforço desses dispositivos durante a pandemia do novo coronavírus.

Em segundo lugar, negar o direito à vida e à saúde dos presos sob a justificativa de uma "guerra" contra o PCC parece fortalecer, mais uma vez, a retórica da organização criminal. Há de se lembrar que a proporção entre os mais de 700 mil custodiados do país integrantes do PCC é relativamente pequena. Portanto, mobilizar essa porcentagem para ratificar a violência cotidiana sobre todos pode ser considerado não só violador como também perigoso. No limite, pode impelir sujeitos que não estejam vinculados ao PCC a reconhecer o crime (e não o Estado) como defensor dos seus direitos. A "metáfora da guerra" problematizada por Leite (2012) continua a permear a configuração social brasileira, quiçá de maneira ainda mais intensa nos últimos tempos. O PCC é identificado com a figura do inimigo, e ao contrário do que pretensamente buscam alcançar, atores estatais acabam por fomentar a "acumulação social da violência", como salientado por Misse (1999, 2009).

Se, nos anos 1990, o PCC se fundou a partir da necessidade de articulação entre as pessoas privadas de liberdade contra um "inimigo" comum, a ameaça agora vem também em formato de vírus. É neste bojo que convergem as lógicas dos grupos criminais, 
Estado e PCC na pandemia: convergências e divergências na proposição de medidas de saúde... Thais Lemos Duarte $\bullet$ Natália Martino • Ana Beraldo

do CNJ, dos órgãos sanitários e de organizações de direitos humanos: a preservação da vida torna-se prioritária a todos esses atores. Em se tratando de uma doença altamente infecciosa, como a Covid-19, as formas de se atingir essa preservação também confluem. No âmbito carcerário, tal ação só pode ser efetuada com o esvaziamento das unidades superlotadas. Como essas medidas não são adotadas de forma satisfatória no país, ocorre a super contaminação dos indivíduos custodiados e uma atualização do antagonismo entre "nós" - presos, criminosos e/ou pobres - e "eles" - o sistema, a Justiça e as classes mais abastadas. A situação consolida a desumanização das pessoas privadas de liberdade, realidade perene no país, o que acaba por revigorar o cenário ideal ao fortalecimento de organizações criminais, como o PCC.

\section{Reflexões finais}

A garantia de direitos a todos os cidadãos, pilar indispensável 31 de um Estado democrático, nunca se efetivou no Brasil, mesmo na pós-redemocratização. Populações marginalizadas por questões raciais, étnicas, econômicas e/ou sociais muitas vezes recebem o tratamento diametralmente contrário ao previsto em lei. E as políticas penais que ensejam o encarceramento em massa, pautadas por forte seletividade, são um braço desse Estado violador e segmentador.

Em cenários de fortes pressões, como o prisional, conjuntos de indivíduos tendem a criar sentimentos de coesão, semeando terreno fértil à criação e ao fortalecimento de organizações criminais, como o PCC. A consolidação do grupo se aprofunda a partir de um misto de violência impetrada por seus membros sobre indivíduos que considera como infratores e dos ganhos financeiros auferidos por meios ilícitos. De igual maneira, o PCC também se torna mais robusto a partir de uma retórica e de ações que implicam a defesa de direitos formais, típicos do Estado democrático, mas que, na prática, não se materializam para todos. 
Estado e PCC na pandemia: convergências e divergências na proposição de medidas de saúde... Thais Lemos Duarte $\bullet$ Natália Martino • Ana Beraldo

A pandemia do novo coronavírus surge, então, como ferramenta potencializadora das diversas variáveis dessa configuração. Quando órgãos estratégicos à pauta penal se negam a seguir as diretrizes nacionais e internacionais de defesa à saúde e à vida dos custodiados, a violação de direitos, que já é uma realidade perene para a população prisional, se aprofunda. Por sua vez, ao denunciar a situação insustentável, ao buscar a articulação com agentes do direito e ao anunciar a contratação de advogados para garantir a efetivação de medidas de contenção da pandemia entre os presos, promovendo a soltura de pessoas com saúde vulnerável, o PCC se fortalece como representante de uma população marginalizada.

Portanto, usar a organização criminal discursivamente para continuar a negar direitos fundamentais aos custodiados de todo o país, tal como vem sendo realizado por certos atores públicos, implica deixar o ambiente prisional mais suscetível ao grupo criminal que dizem querer combater. Instaura-se um ciclo vicioso que articula Estado e PCC sob uma mesma lógica, cujo resultado se distancia cada vez mais dos preceitos de um Estado democrático de Direito. Para romper esse curso, escutar as demandas da população aprisionada por vias formais e atendê-las dentro dos princípios da dignidade humana são medidas fundamentais.

\section{Referências}

ADORNO, Sérgio. Sistema Penitenciário no Brasil: problemas e desafios. Revista USP, São Paulo, s. v., n. 9, p. 65-78, 1991.

ADORNO, Luís. PCC aciona advogados por coronavírus; Justiça manda 1.227 presos para casa. Folha de São Paulo, São Paulo, 07. Jul. 2020. Disponível em: https://noticias.uol.com.br/saude/ ultimas-noticias/redacao/2020/03/30/pcc-aciona-advogados-por-coronavirus-justica-manda-1227-presos-para-casa.htm. Acesso em: 15. set. 2020. 
Estado e PCC na pandemia: convergências e divergências na proposição de medidas de saúde... Thais Lemos Duarte $\bullet$ Natália Martino • Ana Beraldo

ADORNO, Sérgio; DIAS, Camila Nunes. Cronologia dos Ataques de 2006 e a nova configuração de poder nas prisões na última década. Revista Brasileira de Segurança Pública, São Paulo, v. 10, n. 2, p. 118-132, 2016.

AGÊNCIA ESTADO. Saúde dialoga sim com o tráfico, com a milícia, diz Mandetta. Correio Braziliense, Brasília, abr. 2020. Disponível em: https://www.correiobraziliense.com.br/app/noticia/politica/2020/04/08/interna_politica,843289/saude-dialoga-sim-como-trafico-com-a-milicia-diz-mandetta.shtml. Acesso em: 15 set. 2020.

DUARTE, Thaís Lemos; ARAÚJO, Isabela Cristina. PCC em pauta: narrativas jornalísticas sobre a expansão do grupo pelo Brasil. Dilemas - Revista de Estudos de Conflito e Controle Social. Rio de Janeiro, v. 13, n. 2, p. 505-532, 2020.

DUARTE, Thaís Lemos. Vácuo no poder? Reflexões sobre a difusão do Primeiro Comando da Capital pelo Brasil. Revista Crítica de Ciências Sociais, Coimbra, s. v., n. 122, p. 77-96, set. 2020.

AMORIM, Carlos. CV-PCC: a irmandade do crime. Rio de Janeiro: Record, 2004.

AQUINO, Jania P. D.; HIRATA, Daniel. Inserções etnográficas ao universo do crime: algumas considerações sobre pesquisas realizadas no Brasil entre 2000 e 2017. Revista Brasileira de Informação Bibliográfica em Ciências Sociais, São Paulo, v. 84, n. 84, p. 107-147, 2018.

AZEVEDO, Rodrigo Ghiringhelli. Tendência do Controle Penal na Época Contemporânea: Reformas Penais No Brasil e na Argentina. São Paulo em Perspectiva, São Paulo, v. 18, n. 1, p. 39-48, 2004.

BARBOSA, Antônio Rafael. Prender e Dar Fuga: Biopolítica, Sistema Penitenciário e Tráfico de Drogas no Rio de Janeiro. Tese (Doutorado em Antropologia Social) - Museu Nacional, Universidade Federal do Rio de Janeiro, Rio de Janeiro, 2005. 
Estado e PCC na pandemia: convergências e divergências na proposição de medidas de saúde... Thais Lemos Duarte $\bullet$ Natália Martino • Ana Beraldo

BARBOSA, Antônio Rafael. Les études sur la violence et la criminalité au Brésil et les processus de «pacification» dans deux métropoles brésiliennes. Brésil(s). Sciences humaines et sociales, Paris, s. v., n. 9, p. 1-19, 2016.

BAUMAN, Zygmunt. Globalização: As consequências humanas. Rio de Janeiro: Jorge Zahar, 1999.

BIONDI, Karina. Etnografia no movimento: território, hierarquia e lei no PCC. Tese (Doutorado em Antropologia) - Centro de Educação e Ciências Humanas, Universidade Federal de São Carlos, São Carlos, 2014.

BIONDI, Karina. Junto e misturado: uma etnografia do PCC. São Paulo: Editora Terceiro Nome, 2010.

BOZZA, Fábio da Silva. Teorias da pena: do discurso jurídico à crítica criminológica. Rio de Janeiro: Lumem Juris, 2013.

CALDEIRA, Teresa. Violência, direitos e cidadania: relações paradoxais. Ciência e Cultura, São Paulo, v. 54, n. 1, p. 44-46, 2002.

CALDEIRA, Teresa; HOLSTON, James. Democracy and Violence in Brazil. Comparative Studies in Society and History, Cambridge, v. 41, n. 4, p. 691-729, 1999.

CANO, Ignácio; ALVADIA, Alberto. Análise dos Impactos dos Ataques do PCC em São Paulo em Maio de 2006. São Paulo: Laboratório de Análise de Violência e Conectas Direitos Humanos, 2008.

CARLOS, Juliana de Oliveira. Política de drogas e encarceramento em São Paulo, Brasil. Londres: International Drug Policy Consortium, 2015.

CONSELHO NACIONAL DE JUSTIÇA. Boletim Semanal CNJ Covid-19 de 2 de Setembro de 2020. Disponível em https://www. cnj.jus.br/wp-content/uploads/2020/09/Monitoramento-SemanalCovid-19-Info-02.09.20.pdf. Acesso em: 15 de set. 2020. 
Estado e PCC na pandemia: convergências e divergências na proposição de medidas de saúde... Thais Lemos Duarte $\bullet$ Natália Martino • Ana Beraldo

DIAS, Camila. Da pulverização ao monopólio da violência: expansão e consolidação do Primeiro Comando da Capital (PCC) no sistema carcerário paulista. 2011. Tese (Doutorado em Sociologia) - Faculdade de Filosofia, Letras e Ciências Humanas, Universidade de São Paulo, São Paulo, 2011.

DRAKE, Sacha; Karam, Maria Lúcia. Latin American Prisons. In: JEWKES, Y.; BENNETT, J.; CREWE, B. (org.). Handbook on Prisons, 2. ed., Abington: Abington Routledge, 2016. p. 460-474.

FELTRAN, Gabriel. Vinte anos depois: a construção democrática brasileira vista da periferia de São Paulo. Lua Nova: Revista de Cultura e Política, Salvador, s. v., n. 72, p. 83-114, 2007.

FELTRAN, Gabriel. Crime e castigo na cidade: os repertórios da justiça e a questão do homicídio nas periferias de São Paulo. Caderno CRH (UFBA. Impresso), São Paulo, v. 23, n. 58, p. 59-74, 2010.

FELTRAN, Gabriel. Sobre anjos e irmãos: cinquenta anos de expressão política sobre o crime numa tradição musical das periferias. Revista do Instituto de Estudos Brasileiros, São Paulo, s. v., n. 56, pp. 43-72, 2013.

FELTRAN, Gabriel. Governo que produz crime, crime que produz governo: o dispositivo de gestão do homicídio em São Paulo (1992 - 2011). Revista Brasileira de Segurança Pública, São Paulo, v. 2, n. 11, p. 232-255, 2012.

FELTRAN, Gabriel. Irmãos: Uma história do PCC. São Paulo: Companhia das Letras, 2018.

DECLARAÇÃO de ministro da Saúde sobre milícias e tráfico é citada pela ONU e irrita policiais. Folha de São Paulo, São Paulo, 10 abr. 2020. Disponível em: https://www1.folha.uol.com.br/colunas/ painel/2020/04/declaracao-de-mandetta-sobre-milicias-e-trafico-e-citada-na-onu-e-irrita-policiais.shtml. Acesso em: 15 set. 2020.

LEIA a íntegra do discurso de despedida de Moro e entenda ponto a ponto. Folha de São Paulo, São Paulo, 24 abr. 2020. 
Estado e PCC na pandemia: convergências e divergências na proposição de medidas de saúde... Thais Lemos Duarte $\bullet$ Natália Martino • Ana Beraldo

Disponível em: https://www1.folha.uol.com.br/poder/2020/04/ leia-a-integra-do-discurso-de-despedida-de-moro-e-entenda-ponto-a-ponto.shtml. Acesso em: 15 jul. 2020.

FORMAN, James. Children, cops and citizenship: why conservative should oppose racial profiling. In: MAUER, M; CHESNEY-LIND, $M$. The colateral consequences of Mass Imprisonment. Nova York. The New Press, 2012. p. 150-162.

GARLAND, David. A cultura do controle: crime e ordem social na sociedade contemporânea. Rio de Janeiro: Revan, 2008.

GASPARI, Elio. Declaração de Mandetta sobre tráfico e milícia pode ser atribuída à síndrome do holofote. Folha de São Paulo. São Paulo, 12 abr. 2020. Disponível em: https://www1.folha.uol. com.br/colunas/eliogaspari/2020/04/declaracao-de-mandetta-sobre-trafico-e-milicia-pode-ser-atribuida-a-sindrome-do-holofote. shtml. Acesso em: 15 set. 2020.

GIELOW, Igor. Governo faz ofensiva contra soltura de presos devido ao coronavírus. Folha de São Paulo, São Paulo, 7 abr. 2020. Disponível em: https://www1.folha.uol.com.br/equilibrioesaude/2020/04/governo-faz-ofensiva-contra-soltura-de-presos-devido-ao-coronavirus.shtml. Acesso em: 15 set.. 2020.

GRILLO, Carolina Christoph; POLICARPO, Frederico; VERÍSSIMO, Marcos. A "dura" e o "desenrolo": efeitos práticos da nova Lei de Drogas no Rio de Janeiro. In: Revista de Sociologia e Política, v. 19, n. 40, p. 135-148, 2011.

GODOI, Rafael. Fluxos em cadeia: as prisões em São Paulo na virada dos tempos. Tese (Doutorado em Sociologia) - Faculdade de Filosofia, Letras e Ciências Humanas, Universidade de São Paulo, São Paulo, 2015.

GÓES, Eda Maria. A recusa das grades: rebeliões nos presídios paulistas (1982-1986). São Paulo: IBCCrim, 2009.

HIRATA, Daniel. Sobreviver na adversidade: mercados e formas de vida. São Carlos: Edufscar, 2018. 
Estado e PCC na pandemia: convergências e divergências na proposição de medidas de saúde... Thais Lemos Duarte $\bullet$ Natália Martino • Ana Beraldo

JOZINO, Josmar. Cobras e lagartos: a vida íntima e perversa nas prisões brasileiras - quem manda e quem obedece no partido do crime. Rio de Janeiro: Objetiva, 2005.

LEITE, Márcia Pereira. Da "metáfora da guerra" ao projeto de "pacificação": favelas e políticas de segurança pública no Rio de Janeiro. Revista Brasileira de Segurança Pública, São Paulo, v. 6, n. 2, p. 374-389, 2012.

LEEDS, Elizabeth. Cocaine And Parallel Polities In The Brazilian Urban Periphery: Constraints on Local-Level Democratization. Latin American Research Review, Pittsburgh, v. 31, n. 3, p. 47-84, 1996.

LESSING, Benjamin. Counterproductive punishment: How prison gangs undermine state authority. Rationality and Society, Londres, v. 29, n. 3, p. 1-41, 2017.

MANSO, Bruno; DIAS, Camila. PCC, sistema prisional e gestão do novo mundo do crime no Brasil. Revista Brasileira de Segurança Pública, São Paulo, v. 11, n. 2, p. 10-29, 2017.

MANSO, Bruno; DIAS, Camila. A guerra: a ascensão do PCC e o mundo do crime. São Paulo: Todavia, 2018.

MARQUES, Adalton. Crime, proceder, convívio-seguro: um experimento Antropológico partir de relações entre ladrões. 2009. Dissertação (Mestrado em Antropologia) - Faculdade de Filosofia, Letras e Ciências Humanas, Universidade de São Paulo, São Paulo, 2009.

MARQUES, Adalton. "Liderança”, "proceder" e "igualdade": uma etnografia das relações políticas no Primeiro Comando da Capital. Etnográfica, Lisboa, v. 14, n. 2, p. 311-335, 2010.

MARQUES, Adalton. Do ponto de vista do "crime": notas de um trabalho de campo com "ladrões". Horizontes Antropológicos, Porto Alegre, v. 22, n. 45, p. 335-367, jun. 2016.

MARQUES, Adalton. Humanizar e Expandir: uma genealogia da segurança pública em São Paulo. São Carlos, 2017. Tese 
Estado e PCC na pandemia: convergências e divergências na proposição de medidas de saúde... Thais Lemos Duarte $\bullet$ Natália Martino • Ana Beraldo

(Doutorado em Antropologia Social) - Centro de Educação e Ciências Humanas, Universidade Federal de São Carlos, São Carlos, 2017.

MINGARDI, Guaracy. O trabalho da Inteligência no controle do Crime Organizado. Estudos Avançados, São Paulo, v. 21, n. 21, p. 51-69, 2007.

MISSE, Michel. A acumulação social da violência no Rio d e Janeiro. Tese (Doutorado em Sociologia) - IUPERJ-UCAM, Rio de Janeiro, 1999.

MISSE, Michel. Sobre a acumulação social da violência no Rio de Janeiro. Civitas, Porto Alegre, v. 8, n.3, 371-385, 2009.

PADOVANI, Natália Corazza. Sobre casos e casamentos. Afetos e "amores" através das penitenciárias femininas em São Paulo e Barcelona. 2015. Tese (Doutorado em Antropologia Social) Instituto de Filosofia e Ciências Humanas, Universidade Estadual de Campinas, Campinas, 2015.

PAGNAN, Rogério. Justiça de SP concede prisão domiciliar a chefe do PCC que tem hipertensão. Folha de São Paulo, São Paulo, 4 maio 2020. Disponível em: https://www1.folha.uol.com.br/cotidiano/2020/05/justica-de-sp-concede-prisao-domiciliar-a-chefe-do-pcc-que-tem-hipertensao.shtml. Acesso em: 15 set. 2020.

PASTORAL CARCERÁRIA. Tortura em tempos de encarceramento em massa. São Paulo: Pastoral Carcerária Nacional - CNBB, 2016.

PRANDO, Camila. et al. A pandemia do confinamento: políticas de morte nas prisões. Le Monde Diplomatique, 2020.

PERLMAN, Janice. Marginality: from myth to reality in the favelas of Rio de Janeiro, 1969-2002, Institute for Development Policy and Management, University of Manchester, Manchester, UK, 7 a 9 de abril de 2003. Disponível em: https://www.gov.uk/ research-for-development-outputs/marginality-from-myth-to-rea- 
Estado e PCC na pandemia: convergências e divergências na proposição de medidas de saúde... Thais Lemos Duarte $\bullet$ Natália Martino • Ana Beraldo

lity-in-the-favelas-of-rio-de-janeiro-1969-2002. Acesso em: 15 set. 2020.

PORTO, Maria Stella Grossi. Mídia, segurança pública e representações sociais. Tempo Social: Revista de Sociologia da USP, São Paulo, v. 21, n. 2, p. 211-233, 2009.

RODRIGUES, Artur; PAGNAN, Rogério; PAULUZE, Thaiza. Presos fogem e incendeiam objetos em prisões no litoral e no interior de SP. Folha de São Paulo, São Paulo, 16 mar. 2020. Disponível em: https://www1.folha.uol.com.br/cotidiano/2020/03/presos-fogem-e-incendeiam-objetos-prisoes-na-baixada-e-no-interior-de-sp. shtml. Acesso em: 15 set. 2020.

SALLA, Fernando. Decifrando as dinâmicas do crime. Revista Brasileira de Ciências Sociais, São Paulo, v. 30, n. 87, p. 174-179, 2015.

SALLA, Fernando; BALLESTEROS, Paula Rodriguez. Democracia, Direitos Humanos e Condições das Prisões na América do Sul. Relatório de pesquisa, São Paulo, 2008.

SANTANDER Joo et al. La calidad de la democracia en Brasil: un régimen institucionalizado entre la inseguridad individual y desigualdad social. Revista Latinoamericana de Política Comparada, Quito, v. 10, n. 10, p. 87-122, 2015.

SILVESTRE, Giane. (2012). Dias de visita: uma sociologia da punição e das prisões. São Paulo, Brasil: Alameda.

\section{SILVESTRE, Giane. Enxugando o iceberg: como as institui-} ções estatais exercem o controle do crime em São Paulo.

Tese (Doutorado em Sociologia), Centro de Educação e Ciências Humanas, Universidade Federal de São Carlos, São Carlos, 2016.

SINHORETTO, Jaqueline; SILVESTRE, Giane; MELO, Felipe Athayde Lins. O encarceramento em massa em São Paulo. Tempo Social: Revista de Sociologia da USP, São Paulo, v. 25, n. 1. p. 83-106, 2013. 
Estado e PCC na pandemia: convergências e divergências na proposição de medidas de saúde... Thais Lemos Duarte $\bullet$ Natália Martino • Ana Beraldo

SOARES, Luiz Eduardo. Novas políticas de segurança pública.

Estudos avançados, São Paulo, v. 17, n. 17, p. 75-96, 2003.

VALENTE, Rodolfo de Almeida. Guerra de Classe e "Segurança Pública": Sobre as conexões estruturais entre a organização política da violência e a ordenação das relações produtivas no Brasil contemporâneo. 2018. Dissertação (Mestrado em Sociologia) - Instituto de Filosofia e Ciências Humanas, Universidade Estadual de Campinas, Campinas, 2018.

VELASCO, Clara; REIS, Thiago. Com 335 pessoas encarceradas a cada 100 mil, Brasil tem taxa de aprisionamento superior à maioria dos países do mundo. G1, São Paulo, 28 abr. 2020. Disponível em: https://g1.globo.com/monitor-da-violencia/noticia/2019/04/28/com-335-pessoas-encarceradas-a-cada-100-milbrasil-tem-taxa-de-aprisionamento-superior-a-maioria-dos-paises-do-mundo.ghtml. Acesso em: 15 set. 2020.

WACQUANT, Loïc. Les prisons de la misère. Paris: Raisons d'Agir, 1999.

\section{0}

WACQUANT, Loïc. Punishing the poor: The neoliberal government of social insecurity. Columbia: Duke University Press, 2009.

WILLIS, Grahan Denyer. The killing consensus: Police, organized crime, and the regulation of life and death in urban Brazil. Berkeley, University of California Press, 2015.

WILSON, Willian; SAMPSON, Robert. Toward a Theory of Race, Crime and Urban Inequality. In: HAGAN, J.; PETERSON, R.D. Crime and Inequality. Stanford: Stanford University Press; 1995. p. 37-54.

ZALUAR, Alba. Condomínio do diabo. Rio de Janeiro: UFRJ, 1994. 